\title{
Development of an Optimized Algorithm for Bidirectional Equalization in Lithium-Ion Batteries
}

\author{
Jinlei Sun*, Chunbo Zhu*, Rengui Lu*, Kai Song*, and Guo Wei ${ }^{\dagger}$ \\ ${ }^{* \dagger}$ Department of Electrical Engineering and Automation, Harbin Institute of Technology, Harbin, China
}

\begin{abstract}
Many equalization circuits have been proposed to improve pack performance and reduce imbalance. Although bidirectional equalization topologies are promising in these methods, pre-equalization global equalization strategy is lacking. This study proposes a novel state-of-charge (SoC) equalization algorithm for bidirectional equalizer based on particle swarm optimization (PSO), which is employed to find optimal equalization time and steps. The working principle of bidirectional equalization topologies is analyzed, and the reason behind the application of $\mathrm{SoC}$ as a balancing criterion is explained. To verify the performance of the proposed algorithm, a pack with $12 \mathrm{LiFePO} 4$ batteries is applied in the experiment. Results show that the maximum SoC gap is within $2 \%$ after equalization, and the available pack capacity is enhanced by $13.2 \%$. Furthermore, a comparison between previously used methods and the proposed PSO equalization algorithm is presented. Experimental tests are performed, and results show that the proposed PSO equalization algorithm requires fewer steps and is superior to traditional methods in terms of equalization time, energy loss, and balancing performance.
\end{abstract}

Key words: Cell inconsistency, Bidirectional equalization, Equalization strategy, State of charge, Particle swarm optimization

\section{INTRODUCTION}

Lithium-ion batteries are widely used in electric vehicles and hybrid electric vehicles owing to their high energy density and power density characteristics [1]. However, a single cell cannot supply sufficient voltage and capacity for vehicles, and thus connecting cells in a series or in parallel to construct a battery pack is inevitable [2]. Ideally, a pack can be considered high voltage and high capacity if no differences are found among the cells [3]. Nevertheless, variations on capacities, internal resistances, and open-circuit voltage (OCV) occur after batteries are repeatedly charged/discharged because of the manufacturing process and operation environment [4]. Variations also lead to an unbalanced state of charge (SoC) [5], and available pack capacity is limited by the SoC imbalance of cells. Early termination of charge/discharge cycles reduces the available pack capacity because of the strongest and weakest cells [6]. Therefore, monitoring cells in real time and maintaining cell SoCs are recommended to prolong the lifetime

Manuscript received Nov. 13, 2014; accepted Feb. 15, 2015

Recommended for publication by Associate Editor Woo-Jin Choi.

†Corresponding Author: wg_weiguo@sina.com

Tel/Fax: +86-0451-86413621-809, Harbin Institute of Technology

* Department of Electrical Engineering and Automation, Harbin Institute of Technology, China of batteries and retain the available pack capacity.

Numerous equalization methods have been reported in previous studies [7]. N. H. Kutkut is the primary advocate of the passive balancing method [8]. This method bypasses the current from a higher voltage cell by using a parallel resistor. Although this method is simple and easy to control, the excessive energy it produces is transformed into heat, which reduces the available capacity of the battery and induces thermal safety problems. Additionally, the equalization time is long because of low equalization current. Capacitors, inductors, and transformers are utilized to transfer energy from a high charge cell to a low charge cell to overcome the drawbacks of passive equalization [9]-[13]. These methods are called active equalization methods. Among the active methods, the switching capacitor method requires no closed loop or sensing [6]. However, it is not accurate because the hysteresis effect is not considered. Korea Advanced Institute of Science and Technology (KAIST) proposed various topologies that use transformers, switching blocks, and sensing circuits [14]. Nevertheless, KAIST focused only on new topology development, and few equalization strategies were involved in its research. To improve efficiency and decrease switching loss, Yuang-Shung Lee further developed existing methods with soft switching technology [13], [15]. However, when cell voltage is 
taken as a criterion, soft switching complicates the circuit further.

Bidirectional equalization equipped with voltage acquisition module is a promising method to achieve fast and accurate battery equalization because of bidirectional energy transfer and fast equalization speed. A current closed loop can also be used to accurately estimate the charge delivered, and algorithms based on SoC can be applied. Thus, a bidirectional full-bridge converter with a switching block is utilized in this study for cell balancing.

Bidirectional full-bridge topology determines that energy is transferred between a pack and a cell [16]. When a single cell is charged or discharged for balancing, the current runs through the other cells. Determining final cell target SoCs for equalization is difficult in this case. Traditional equalization methods take voltage as a balancing criterion, but charge differences exist among cells with the same voltage because of over potential [17], [18]. Some researchers focused on the SoC equalization method [19], [20]. These researchers aimed to minimize the differences between the mean SoC of a pack and a specific battery by balancing. However, this method lacks global target consideration for equalization, which may cause energy loss and long equalization time.

To solve these problems, a novel SoC equalization algorithm for bidirectional equalizer is proposed based on particle swarm optimization (PSO). PSO algorithm optimizes the equalization time for each cell based on the pack initial SoC distribution. The working principle for bidirectional equalization topologies is analyzed, and the reason for taking SoC as a balancing criterion is explained. PSO algorithm is applied to obtain the global optimal solution to improve the balancing speed. The performance of the proposed algorithm in enhancing pack available capacity is confirmed through an experiment, and a comparison between the previous methods used in references and the proposed method is presented. The experimental results verify the advantages of the proposed PSO equalization algorithm.

\section{BIDIRECTIONAL SOC EQUALIZATION}

\section{A. Bidirectional Equalization Topology}

Fig. 1 shows a bidirectional equalization circuit with a switching block. The switching block is used to connect the target cell to a DC/DC converter. The main circuit of the bidirectional DC/DC converter is based on a transformer, and the circuit works in two modes according to the energy flow. In the charge mode, the switching block selects the target cell with low charge, and energy flows from the pack to the target cell [Fig. 2(a)]. In the discharge mode, energy is transferred from the target cell to the pack [Fig. 2(b)]. The arrow in Fig. 2 indicates the current direction. Many transformer-based DC/DC converters can be bidirectional [11], [20].

Equalization current is critical to analyze the energy transfer

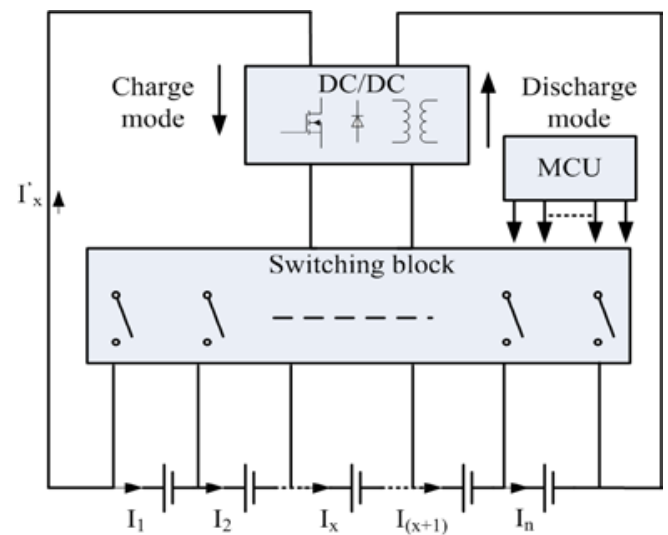

Fig. 1. Structure of bidirectional equalization circuit.

during equalization. As long as the equalization current for the target cell and the efficiency for the charge/discharge mode are obtained, the current that passes through the other cells can be calculated using either Eq. (1) or (2).

$$
\begin{aligned}
& \mathrm{I}_{\mathrm{x} \_ \text {charge }}^{\prime}=\frac{\mathrm{V}_{\mathrm{x}} \cdot \mathrm{I}_{\mathrm{x} \_ \text {charge }}}{\mathrm{V}_{\mathrm{x}}+\eta_{\text {charge }} \sum_{\mathrm{i}=1}^{\mathrm{n}} \mathrm{V}_{\mathrm{i}}}, \\
& \mathrm{I}_{\mathrm{x}_{\text {_discharge }}}^{\prime}=\frac{\eta_{\text {discharge }} \mathrm{V}_{\mathrm{x}} \cdot \mathrm{I}_{\mathrm{x}_{\_} \text {discharge }}}{\eta_{\text {discharge }} \mathrm{V}_{\mathrm{x}}+\sum_{\mathrm{i}=1}^{\mathrm{n}} \mathrm{V}_{\mathrm{i}}},
\end{aligned}
$$

where $V_{i}$ is the voltage of cell i. $V_{x}$ is the voltage of target cell $x, I_{x}$ is the current that passes through target cell $x$, and $\mathrm{I}_{\mathrm{x}}^{\prime}$ is the current of the other cells. $\eta_{\text {charge }}$ is the efficiency for the charge mode, whereas $\eta_{\text {discharge }}$ is that for the discharge mode.

Cell SoCs and transferred charge are required for accurate equalization. Cell SoCs and equalization time are discussed in Section II(B) and Section III respectively.

\section{B. SoC Equalization}

This work has two assumptions. First, cells are screened before grouping, which means the slight capacity difference is not a concern in analysis. Second, the cell coulombic efficiency is 1 .

The cell SoC is calculated using the remaining and nominal cell capacities. The definition is as follows:

$$
\text { SoC }=\mathrm{C}_{\mathrm{R}} / \mathrm{C}_{\mathrm{N}} \text {. }
$$

The remaining capacity is calculated through Eq. (4):

$$
\mathrm{C}_{\mathrm{R}}=\mathrm{SoC}_{0} \times \mathrm{C}_{\mathrm{N}}+\int_{t_{0}}^{t}\left(\mathrm{I}(\mathrm{t})+\mathrm{I}_{\mathrm{E}}\right) \mathrm{dt},
$$

where $\mathrm{SOC}_{0}$ is the initial cell SoC, and $\mathrm{C}_{\mathrm{N}}$ is the nominal cell capacity. The Ah change in a certain period is integrated from $t_{0}$ to $t$. $I(t)$ is the current at time $t$, and $I_{E}$ is 

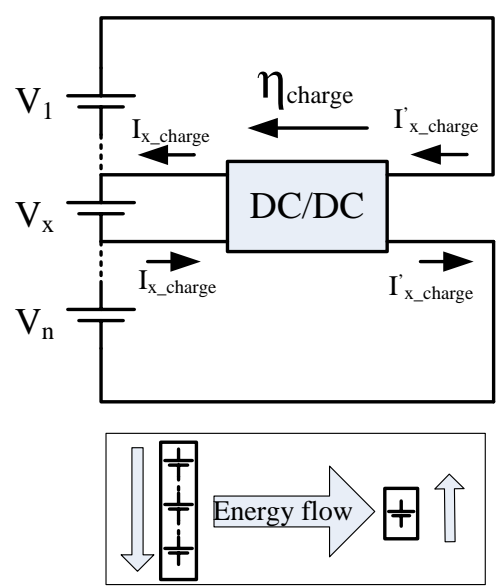

(a)

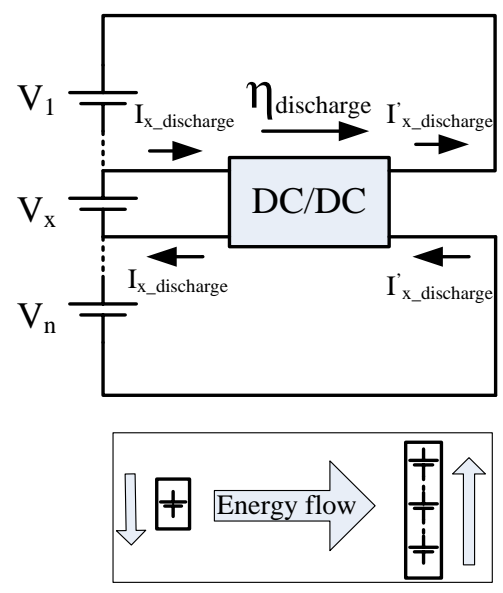

(b)

Fig. 2. Working modes for balancing. (a) Charge mode for balancing. (b) Discharge mode for balancing.

the equalization current.

Eq. (4) shows that the initial SoC is important to estimate the remaining capacity. Numerous methods have been developed to accurately estimate the initial SoC [21], [22]. Most of the methods are based on the nonlinear function between SoC and OCV. Reference [22] indicated that cell voltage is close to OCV in an equilibrium state, and that the curves for charging and discharging are not overlapped because of the hysteresis effect [5].

The pack current can be calculated through Eqs. (1) and (2). Furthermore, the SoC variation for the charging and discharging modes can be described as Eqs. (5) and (6) respectively.

$$
\begin{gathered}
\operatorname{SoC}_{\mathrm{X}}+\operatorname{sgn}\left(\mathrm{I}_{x_{-} \text {cell }} \cdot \mathrm{t}_{\mathrm{X}} / \mathrm{C}_{\mathrm{N}}\right)=\operatorname{SoC}_{\mathrm{X}}^{\prime}, \\
\operatorname{SoC}_{\mathrm{Y}}+\operatorname{sgn}\left(\mathrm{I}_{x_{-} \text {pack }}^{\prime} \cdot \mathrm{t}_{\mathrm{X}} / \mathrm{C}_{\mathrm{N}}\right)=\operatorname{SoC}_{\mathrm{Y}}^{\prime},
\end{gathered}
$$

where $\mathrm{SOC}_{\mathrm{x}}$ and $\mathrm{SOC}_{\mathrm{x}}^{\prime}$ accordingly represent the SoCs before and after a balancing step for the target cell, and $\mathrm{SOC}_{\mathrm{Y}}$ and $\mathrm{SOC}_{\mathrm{Y}}^{\prime}$ are the respective initial and final SoCs

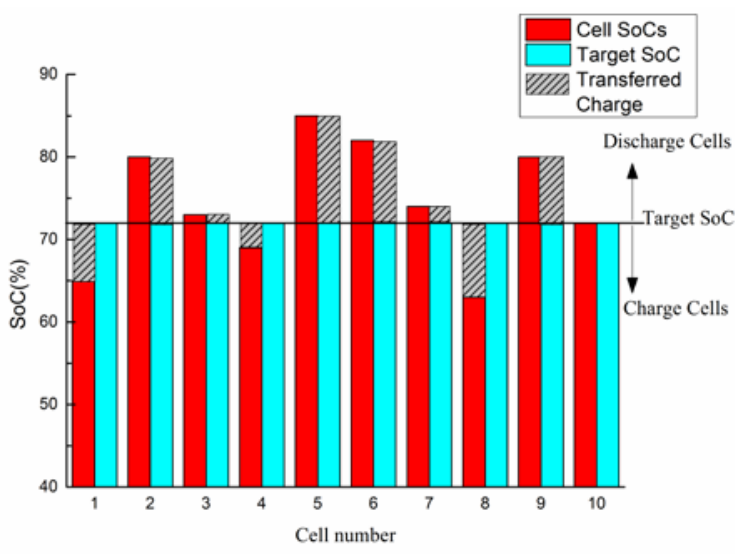

Fig. 3. Diagram for SoC equalization.

for the cell in the pack other than the target cell in the pack. When $I_{x_{-} \text {cell }}$ is measured, $I_{x_{-} p a c k}^{\prime}$ can be obtained according to Eqs. (1) and (2). In Eqs. (5) and (6), sgn indicates the current direction. When a cell is discharging, the sgn for the cell in Eq. (5) is negative, whereas the sgn for the pack in Eq. (6) is positive.

$$
\mathrm{t}_{\text {total }}=\sum_{i=1}^{n} t_{i} .
$$

For a pack with $\mathrm{n}$ cells that are series connected, the total equalization time is the sum of the time consumed to balance each cell. The total balancing time is described in Eq. (7).

According to the above analysis, the total equalization time is determined according to the final target SoC of each cell. Thus, the algorithm to decrease the time and step for equalization is focused on. Section III introduces the details.

\section{PSO EQUALIZATION STRATEGY}

\section{A. SoC Equalization Analysis}

In the study of equalization strategy, determining the goal for the ending of balancing is an important factor influencing performance and accuracy. To achieve accurate equalization, SoC is taken as a criterion in many previous studies to describe charge inconsistency [20], [23]. Fig. 3 shows the energy transfer of SoC based on equalization. Obtaining the charge to be balanced for each equalization step is the key to achieving the final SoC consistencies. The final SoCs for the cells in a pack can be calculated using Eqs. (5) and (6).

For a pack with $n$ cells connected in a series, the equalization process contains $\mathrm{n}$ steps, assuming that each cell takes one equalization step. If the charge transferred in each step is obtained, the current direction vector $\mathrm{M}$ can be achieved. In $\mathrm{M}$, 1 represents discharging, whereas -1 represents charging. For each step, the equalization current for the target cell causes the corresponding current to pass through the other cells. This process can be described as an equation to show the charge 
variation for each cell. The charge variation for all the cells can also create an equation set, as shown in Eq. (8).

$$
\begin{aligned}
& \mathrm{I}_{1_{-} \text {cell }} t_{1}-\mathrm{I}_{1_{-} \text {pack }}^{\prime} t_{2}-\cdots \cdots-\mathrm{I}_{1_{-} \text {pack }}^{\prime} t_{n-1}-\mathrm{I}_{1_{-} \text {pack }}^{\prime} t_{n}=\Delta C_{1} \\
& -\mathrm{I}_{2 \_ \text {pack }}^{\prime} t_{1}+\mathrm{I}_{2_{-} \text {cell }} t_{2}-\cdots \cdots-\mathrm{I}_{2_{-} \text {pack }}^{\prime} t_{n-1}-\mathrm{I}_{2_{-} \text {pack }}^{\prime} t_{n}=\Delta C_{2} \\
& \begin{array}{llllll}
\vdots & \vdots & \ddots & \vdots & \vdots & \vdots
\end{array} \\
& \begin{array}{lllllll}
\vdots & \vdots & \ddots & \vdots & \vdots & \vdots \\
\vdots & \vdots & & \ddots & \vdots & \vdots & \vdots
\end{array} \\
& -\mathrm{I}_{n-1 \_ \text {pack }}^{\prime} t_{1}-\mathrm{I}_{n-1 \_ \text {pack }}^{\prime} t_{2}-\cdots \cdots+\mathrm{I}_{n-1 / \text { cell }} t_{n-1}-\mathrm{I}_{n-1, \text { pack }}^{\prime} t_{n}=\Delta C_{n-1} \\
& -\mathrm{I}_{n_{-} \text {pack }}^{\prime} t_{1}-\mathrm{I}_{n_{-} \text {pack }}^{\prime} t_{2}-\cdots \cdots-\mathrm{I}_{n_{-} \text {pack }}^{\prime} t_{n-1}+\mathrm{I}_{n_{-} \text {cell }} t_{n}=\Delta C_{n}
\end{aligned}
$$

where $t_{1} \cdots t_{n}$ are the equalization times for each cell, and $\Delta \mathrm{C}_{1} \cdots \Delta \mathrm{C}_{\mathrm{n}}$ are the charge variations for cell $\mathrm{n}$ in the corresponding equalization steps. All the subscripts represent the number of cells.

Equation (8) can be expressed as follows:

$$
A x=B \text {, }
$$

where $X$ is the equalization time vector, $B$ is the total charge variation vector, and $A$ is the current vector. These vectors are shown as follows:

$$
\begin{aligned}
& x=\left(\begin{array}{llll}
t_{1} & t_{2} & \cdots & t_{n-1} \\
t_{n}
\end{array}\right)^{\mathrm{T}}, \\
& B=\left(\Delta C_{1} \Delta C_{2} \cdots \Delta C_{n-1} \Delta C_{n}\right)^{\mathrm{T}} \text {, }
\end{aligned}
$$

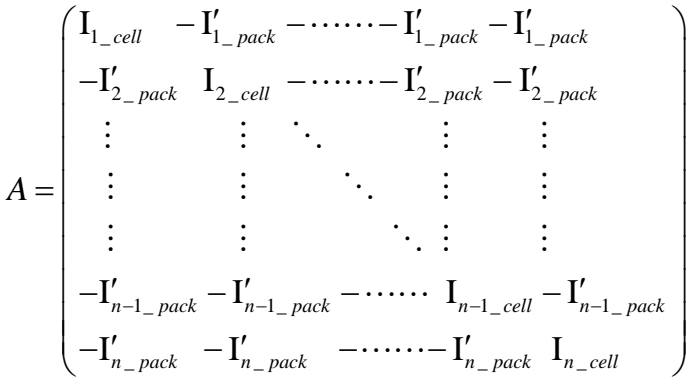

\section{B. Problem Formulation}

This work aims to provide a method to minimize equalization time and improve SoC consistency. Eqs. (8)-(12) clearly show that the equalization time for each cell, which is a significant factor for users to predict the total time consumed, can be calculated as long as the charge variations are determined. The equalization current vector $\mathrm{A}$ is determined as the circuit characterizes the bi-directional equalizer. Notably, when a cell is charging/discharging, a current goes through the other cells because of the structure of the bidirectional equalizer. Hence, the target SoC for each cell to be charged/discharged is difficult to predict. The crucial issue is to obtain a set of charge variations to solve the equalization time and direction for each cell. Although enumeration is a promising method to find the solution, the large calculation and long searching time are the main disadvantages that limit the application in this work. For instance, the possible cell charge variation range is between -5 and 5 Ah with 0.1 Ah minimum resolution; the best solution is among $100^{12}$ results for a pack with 12 cells. The enumeration method incurs large calculations and is time consuming. Therefore, a mathematical method is required to seek the global optimal solution with less calculation. Finally, the PSO algorithm is applied in this work.

\section{PSO Algorithm}

The idea of the PSO algorithm is inspired by the behavior of birds. Kennedy and Elberhart [24] initially proposed this method in 1995. The PSO algorithm has advantages such as simple coding and few parameters, and has been widely used in the field of function optimization. The main idea of this algorithm is that each solution is called a particle with n-dimensional space, and fitness function is used to evaluate the degree of superiority of each particle. Velocity and position are two important parameters. Position is the potential result of a problem. The PSO algorithm flow is shown in Fig. 4.

In this work, position denotes a set of charge variations that can be used to calculate equalization time and current direction for each cell. Additionally, particle velocity represents the charge variations in each iteration. Position and velocity are updated according to fitness function to seek the global optimal solution and the individual optimal solution. With the acquired global optimal charge variation vector, the corresponding equalization time and current direction can be obtained via Eq. (8).

The choice of fitness function greatly influences the performance of PSO optimization. Fitness function is determined by the goal of minimizing equalization time and SoC inconsistency. Thus, fitness function is defined as

$$
f\left(t_{\mathrm{i}}\right)=\min \left(\left(\sum_{\mathrm{i}=1}^{n} t_{\mathrm{i}}\right)^{2}+\frac{1}{n} \sum_{i=1}^{n}\left(y\left(t_{\mathrm{i}}\right)-\overline{y\left(t_{\mathrm{i}}\right)}\right)^{2}\right) .
$$

In Eq. (13), $y\left(t_{i}\right)$ represents the final SoC for each cell, which is a function of time $t_{\mathrm{i}}$, and can be calculated through Eqs. (5) and (6). $\overline{y\left(t_{\mathrm{i}}\right)}$ is the mean of $y\left(t_{\mathrm{i}}\right)$.

The proposed PSO algorithm for battery SoC equalization in this work is an off-line optimization method. The equalization time and current direction are calculated using a computer, and the equalization instructions are transferred to the target equalizer for operation.

The steps for the PSO equalization algorithm are as follows:

1. PSO parameters such as particle number, maximum velocity, and largest iteration times are set. Adaptive weight coefficient is adopted in this method [25]. The definition is as follows:

$$
w(k)=w_{\max }-\frac{w_{\max }-w_{\min }}{\text { iter }} k,
$$

where $w_{\max }$ and $w_{\min }$ are the maximum and minimum inertia weight coefficients respectively, iter 


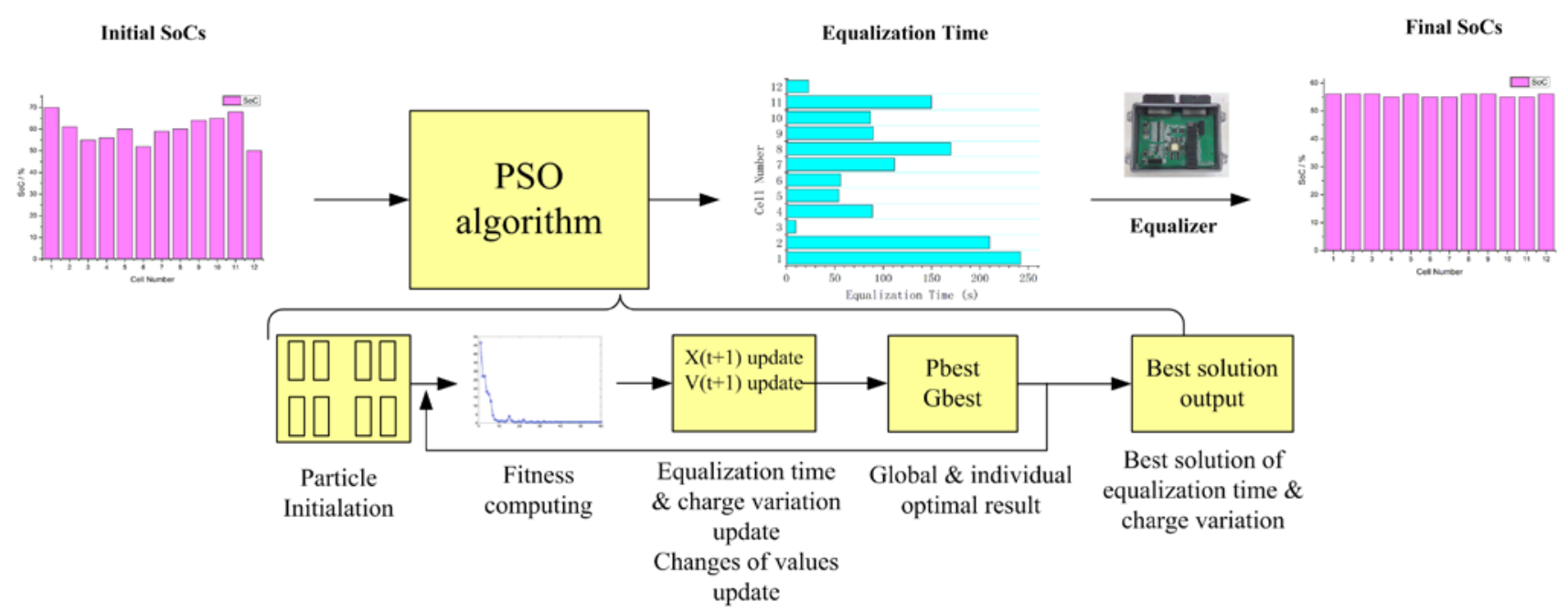

Fig. 4. Flowchart of PSO equalization algorithm.

is the largest iteration time, and $\mathrm{k}$ is the iteration time.

2. Velocity and position are initiated randomly.

3. The fitness value of each particle is calculated, and velocity and position are updated according to Eqs. (15) and (16).

4. The new velocity and position are compared with the previous ones. If the fitness of the new particle is smaller than the individual extremum pbest that exists, the pbest is updated. Otherwise, the previous pbest is retained.

5. The global optimal solution gbest is obtained according to the individual fitness of every particle.

6. Step 3 is executed.

7. The optimal solution is obtained.

$$
\begin{aligned}
& v_{i d}(t+1)=w v_{i d}(t)+c_{1} r_{1}\left(p_{i d}(t)-x_{i d}(t)\right)+ \\
& c_{2} r_{2}\left(p_{g d}(t)-x_{i d}(t)\right) \\
& x_{i d}(t+1)=x_{i d}(t)+v_{i d}(t+1)
\end{aligned}
$$

where $v_{i d}$ is the velocity of the particle, $x_{i d}$ is the place of the particle , $p_{i d}$ is the individual extremum of the particle at present, $p_{g d}$ is the global optimal solution of the whole group, $t$ is the iteration, $d$ is the space dimension, i represents the number of particle, and $c_{1}$ and $c_{2}$ are the acceleration constants. $r_{1}$ and $r_{2}$ are randomly set in $[0,1]$, and $\mathrm{w}$ is the inertia weight coefficient.

MATLAB is employed to solve the PSO optimization problem. The parameters for the PSO algorithm are listed in Table I. The largest iteration time is 100 , and the number of particles is 40 . The acceleration constants are set as 2. The adoptive weight coefficient is defined as $w(k)$. Some constraints exist for the optimization of balancing, as shown in Table I as well.

The constraints for this problem include equalization time, initial SoC for cell x before equalization $S_{0} C_{x}^{\text {inital }}$, final SoC for cell $\mathrm{x}$ after equalization $\operatorname{SoC}_{x}^{\text {final }}$, and charge variation for cell $\mathrm{x}$ during equalization $\Delta C_{x}$. The equalization time should be greater than 0 ; thus, the first constraint is $t_{x}>0$. The charge variation for cell $\mathrm{x}$ after $\mathrm{n}$ steps of equalization is expressed as $\Delta C_{x}$, which can be below or above zero. The maximum charge variation should not be larger than the cell capacity $C_{N}$. Thus, the second constraint is $-C_{N}<\Delta C_{x}<$ $C_{N}$. The initial SoC and final SoC for cell $\mathrm{x}$ should all be within the range of $0 \%$ and $100 \%$; thus, the third constraint is $0 \%<\operatorname{SoC}_{x}^{\text {inital }}<100 \% \quad$ and $\quad 0 \%<\operatorname{SoC}_{x}^{\text {final }}<100 \%$. SoC $_{x}^{\text {final }}$ can be calculated through Eqs. (5) and (6).

\section{EXPERIMENT DESIGN}

\section{A. Experiment Object}

To verify the performance and effectiveness of the proposed algorithm, a pack with 12 LiFePO4 cells connected in a series was implemented. The nominal cell capacity was $5 \mathrm{Ah}$, and the nominal voltage was 3.2 V. The upper and lower voltage limits were 3.65 and $2.5 \mathrm{~V}$ respectively. The experiments were taken under idle condition.

\section{B. Battery Screening}

To reduce the influence of capacity variation, the cells were screened before grouping. Moreover, the steps for the cell capacity measurement were as follows:

1) Preparation step. Discharge at $1 \mathrm{C}$ rate until the discharge cutoff voltage was reached. 
TABLE I

PARAMETERS FOR PSO ALGORITHM

\begin{tabular}{ll}
\hline \multicolumn{1}{c}{ Parameters } & \multicolumn{1}{c}{ Value } \\
\hline Fitness function & $f\left(t_{\mathrm{i}}\right)=\min \left(\left(\sum_{\mathrm{i}=1}^{n} t_{\mathrm{i}}\right)^{2}+\frac{1}{n} \sum_{i=1}^{n}\left(y\left(t_{\mathrm{i}}\right)-\overline{y\left(t_{\mathrm{i}}\right)}\right)^{2}\right)$ \\
Maximum iteration & 40 \\
Number of particles & $w(k)=w_{\max }-\frac{w_{\max }-w_{\min }}{i t e o r}$, \\
Weight coefficient w(k) & $w_{\max }=0.9 ; w_{\min }=0.4$ \\
& 2 \\
Acceleration constant c1 & 2 \\
Acceleration constant c2 & $t_{x}>0,-C_{N}>\Delta C_{n}>C_{N}$ \\
Constraints & $0 \%<$ So $_{x}^{\text {inital }}<100 \%, 0 \%<$ SoC $_{x}^{\text {final }}<100 \%$ \\
& $\mathrm{~N}$, \\
\hline
\end{tabular}

2) Resting for $5 \mathrm{~h}$ to alleviate the influence of polarization.

3) Charging at $1 \mathrm{C}$ rate constant current until charge cutoff voltage was reached.

4) Charging with CV until the current decreased to $0.05 \mathrm{C}$.

5) Resting for $5 \mathrm{~h}$ to alleviate the influence of polarization.

6) Discharging until the discharge cutoff voltage was reached

7) Defining the discharge capacity as the cell capacity.

Ref. [26] reported that the SoCs complied with normal distribution after being repeatedly charged and discharged. The pack should be replaced when the available pack capacity loss reached 20\% [5]. Thus, the initial SoC distribution in this work was arranged to comply with a normal distribution with $40 \%$ mean and 5\% variance. Each cell was charged artificially to obtain the SoC distribution, as shown in Fig. 5, where the maximum and minimum SoCs were $49.8 \%$ and $29.3 \%$ respectively.

\section{Measurement Equipment}

All the tests were performed with a channel of an Arbin instrument BT2000 (18 V, $\pm 100 \mathrm{~A})$, which had a voltage measurement accuracy of $\pm 0.01 \%$ and a current measurement accuracy of $\pm 0.02 \%$ on the full-scale value. Moreover, the ambient temperature was at $25{ }^{\circ} \mathrm{C} \pm 5{ }^{\circ} \mathrm{C}$. The hardware for equalization was based on bidirectional full-bridge equalizer [16]. The diagram of the circuit is shown in Fig. 6. The main parts of the system included a full-bridge converter, a switching block, and a controller. The switching frequency of the converter was $30 \mathrm{kHz}$ with maximum duty cycle of $45 \%$. The equalization current parameters were obtained by a board using Hall-effect sensors. The details are shown in Table II. An LTC6803-based measurement board with a $5 \mathrm{mV}$ maximum measurement error was used to measure the cell voltage. All the measured equalization information were sent through a controller area network (CAN) bus for data storage and display. The experimental setup is shown in Fig. 7.

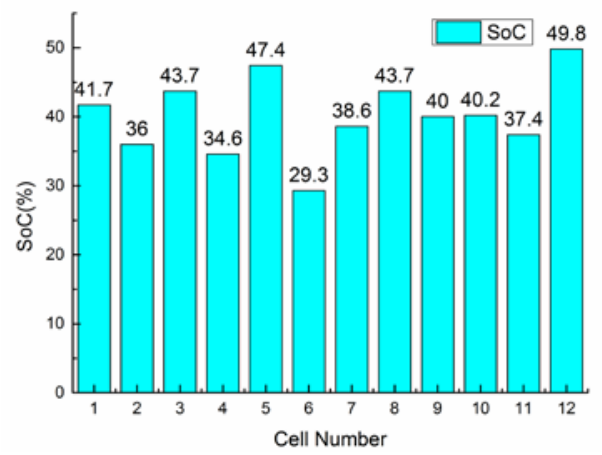

Fig. 5. Initial pack of SoC distribution.

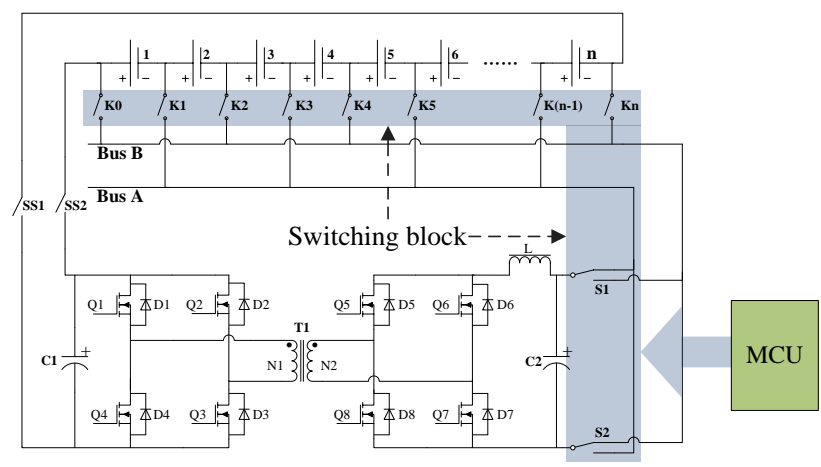

Fig. 6. Bidirectional full-bridge equalization topology.

TABLE II

CURRENT PARAMETERS FOR EQUALIZATION

\begin{tabular}{lll}
\hline & Target Cell Current & Other Cells \\
\hline Pack-cell & $2.45 \mathrm{~A}$ & $0.3 \mathrm{~A}$ \\
Cell-pack & $2.25 \mathrm{~A}$ & $0.1 \mathrm{~A}$ \\
\hline
\end{tabular}

\section{Experimental Procedure}

Two validation tests were conducted under the same ambient temperature $\left(25^{\circ} \mathrm{C} \pm 5^{\circ} \mathrm{C}\right)$ with the same experimental setup. 


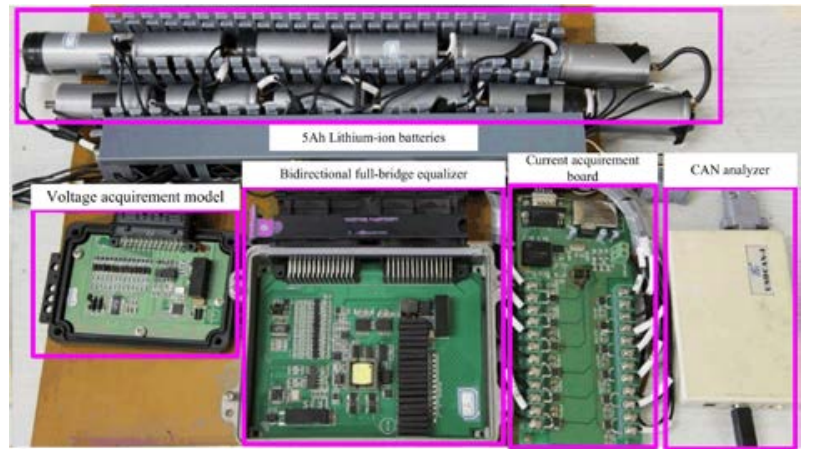

Fig. 7. Photograph of experimental setup.

The SoC distribution with 20.5\% maximum SoC gap was used in the two tests. Fig. 5 shows the SoC distribution. The two tests were arranged as follows.

Test 1: The validation experiment was performed on the pack to verify the performance of the proposed method. The charge and discharge cycle was taken before and after equalization respectively.

Test 2: Comparative experiments were performed between the traditional methods and the proposed algorithm to verify the superiority of the algorithm.

\section{RESULTS AND DISCUSSION}

\section{A. Validation of the PSO Equalization Algorithm}

The proposed PSO equalization algorithm was applied to the pack mentioned in Section IV B. The equalization time and charge variation were calculated using an Intel Xeon E5-2620 $2.0 \mathrm{GHz}$ processor with $32 \mathrm{~GB}$ of RAM. The average executed time was $55.53595 \mathrm{~s}$. The obtained equalization instructions were sent to a micro-control unit-based equalizer through a CAN bus. The equalizer controlled the equalization time and the current direction according to the PSO algorithm result to achieve SoC balancing.

Fig. 8 shows the calculated optimized equalization results for each cell using the PSO algorithm. In Fig. 8a , a positive value means charging, whereas a negative value means discharging. The SoC gap was reduced from $20.5 \%$ to $1.11 \%$ within $58 \mathrm{~min}$ and $42 \mathrm{~s}$. The comparison of the SoC distribution before and after equalization is shown in Fig. 9.

Fig. 10 shows the test results before and after equalization. In Fig. 10a, the initial discharge capacity was 1.44 Ah because of the minimum SoC of cell 6 , and the charge and discharge capacity were 3.39 and 3.35 Ah respectively. In this cycle, Cell 12 ended the charging first, while Cell 6 ended the discharging initially. In Fig. 10b, the initial discharge capacity was $1.85 \mathrm{Ah}$ with Cell 4 reaching the discharge cutoff voltage first, rather than Cell 6 . In addition, the charge and discharge capacity were 4.05 and 4.01 Ah respectively. In this cycle, Cell 8 ended the charging first, and Cell 4 ended the discharging initially. The available discharge capacity was enhanced by up to $13.2 \%$

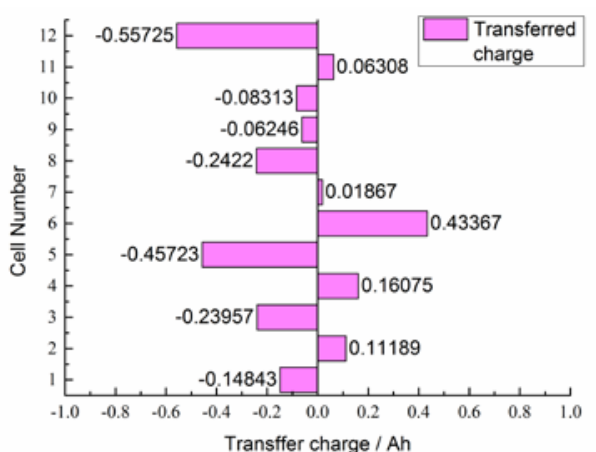

(a)

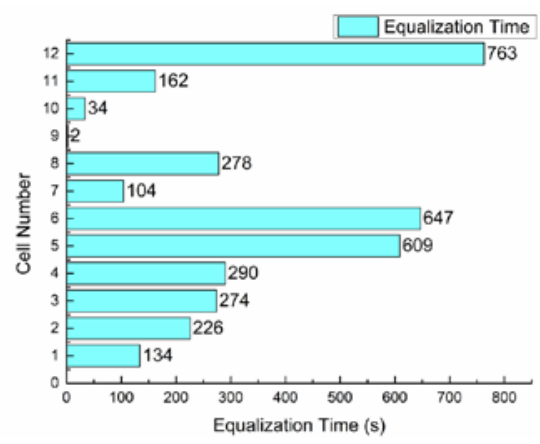

(b)

Fig. 8. Equalization results of (a) charge transfer for each cell. (b) Equalization time for each cell

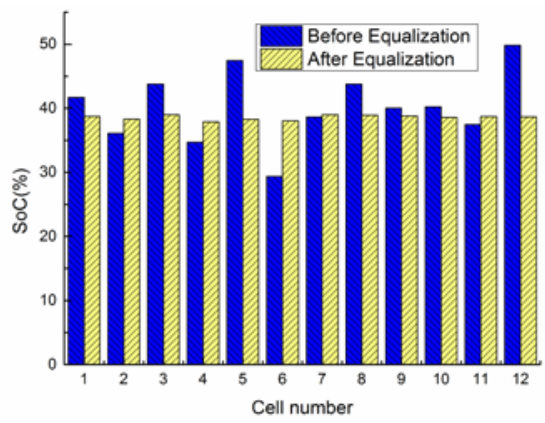

Fig. 9. Comparison of SoC distribution before and after equalization

using the equalization method based on the PSO algorithm.

The comparison shows that the pack available capacity was influenced by the maximum SoC and minimum SoC in the pack. The cell with maximum SoC reached the charge cutoff voltage first during charging, and the cell with a minimum SoC reached the discharge cutoff voltage first during discharging. Before equalization, the minimum and maximum SoCs were $29.3 \%$ and $49.8 \%$ respectively. However, after equalization, the difference was within $2 \%$. The result proved that the bidirectional equalization circuit with the proposed algorithm was effective in improving the inconsistency and enlarging the available pack capacity range.

\section{B. Comparative study of the Proposed Method}

In this section, the proposed PSO equalization algorithm was 


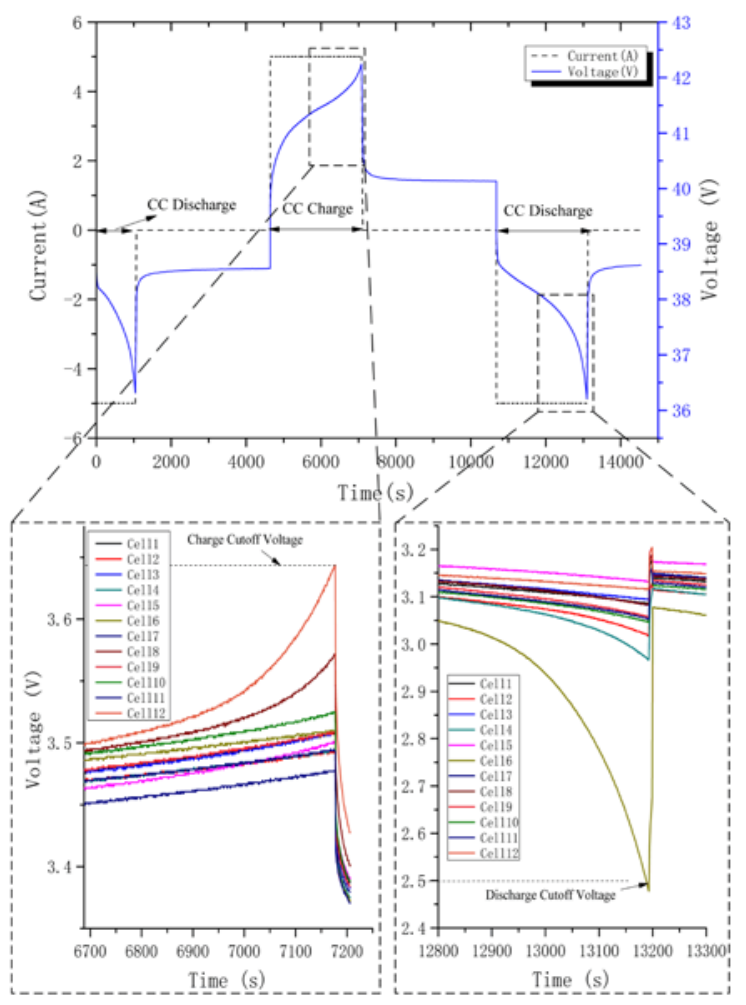

(a)

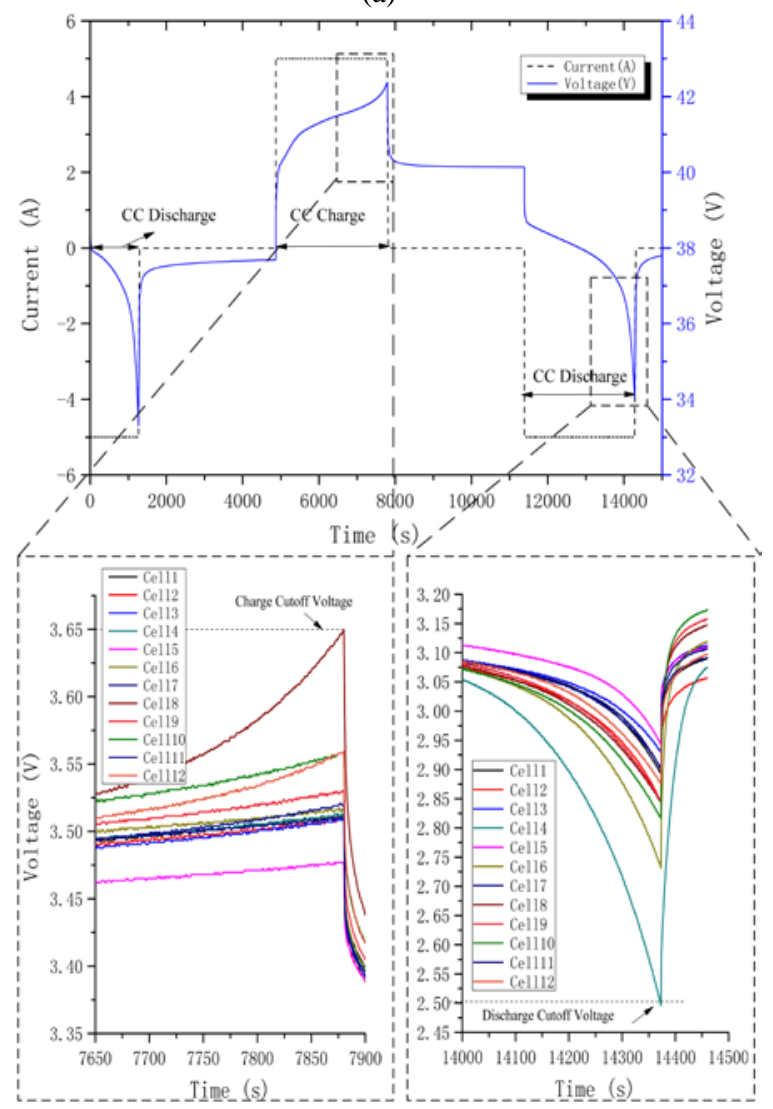

(b)

Fig. 10. Comparison of results: (a) charge and discharge cycles before equalization and (b) charge and discharge cycle after equalization compared with traditional methods. The comparative experiments were divided into two groups.

Group 1: The initial SoC distribution shown in Fig. 5 was implemented in the proposed PSO algorithm and in a method based on mean difference [20]. The method in Ref. [20] minimized the differences between the mean SoC of the pack and a specific battery unit through balancing. The same strategy was utilized in method 1. For the proposed PSO algorithm, the obtained equalization time and current direction were the optimized global solution. As for method 1, the equalization time for each cell was calculated according to the charge difference between the mean SoC and the SoC of the target cell to be balanced. The comparison of the equalization process is shown in Table III.

Clearly, the PSO method required only 12 steps to finish equalization, whereas method 1 required 14 steps. Hence, cells 1 and 2 suffered one additional equalization step each. The equalization time for the average SoC approximation method was longer, and more loss and resource consumption were generated than the proposed PSO method. In addition, the SoC root mean square of both methods decreased as the equalization step progressed, but the final result for the PSO method was less than that of method 1 . The equalization results for the two methods in group 1 are shown in Table IV.

Group 2: The proposed PSO method was conducted under the same condition of the initial SoC distribution as Refs. [14] and [16]. The initial SoC state was given in Ref. [14], while the initial SoC state in Ref. [16], which was not presented directly, was calculated according to the OCV-SoC curve for charging and the charge quantity deviation. The comparison results are shown in Table V. The method used in Refs. [14] and [16] are named as methods 2 and 3 respectively in Table V. As shown in Tables IV and V, the proposed PSO method has excellent performance on minimizing equalization time and improving SoC consistency compared with the other methods. The proposed PSO method also consumed less energy than method 1 during equalization.

\section{System Energy Loss Analysis}

Assuming that the number of cells required for charging and discharging are $\mathrm{p}$ and $\mathrm{q}$ respectively, the energy loss for all the charging and discharging processes are as follows:

$$
\begin{aligned}
& W_{\text {cha_loss }}=\sum_{\mathrm{i}=1}^{p}\left[\mathrm{I}_{\text {charge }}^{\prime} \cdot V_{\text {pack }}-\mathrm{V}_{\mathrm{i}} \cdot\left(\mathrm{I}_{\text {charge }}-\mathrm{I}_{\text {charge }}^{\prime}\right)\right] \cdot t_{i}, \\
& W_{\text {disch_loss }}=\sum_{\mathrm{j}=1}^{q}\left[\mathrm{~V}_{j} \cdot\left(\mathrm{I}_{\text {discharge }}-\mathrm{I}_{\text {discharge }}^{\prime}\right)-\mathrm{I}_{\text {discharge }}^{\prime} \cdot V_{\text {pack }}\right] \cdot t_{j},
\end{aligned}
$$

where $V_{\text {pack }}$ is the sum of the cell voltage in a pack, $V_{i}$ is the voltage of cell $\mathrm{i}, \mathrm{V}_{j}$ is the voltage of cell $\mathrm{j}, t_{i}$ and $t_{j}$ are the equalization time for cells $\mathrm{i}$ and $\mathrm{j}$ respectively, and $\mathrm{I}_{\text {charge }}$ and $I_{\text {charge }}^{\prime}$ are the currents that go through the single cell and the other cells in charge mode respectively. $\mathrm{I}_{\text {discharge }}$ 
TABLE III

COMPARISON OF THE EQUALIZATION PROCESSES

\begin{tabular}{|c|c|c|c|c|c|c|}
\hline & \multicolumn{3}{|c|}{ PSO algorithm } & \multicolumn{3}{|c|}{ Method 1} \\
\hline Step & $\begin{array}{l}\text { Current } \\
\text { flow }\end{array}$ & $\begin{array}{l}\text { Equalization step time } \\
\text { (s) }\end{array}$ & $\begin{array}{l}\text { SoC root mean } \\
\text { square }\end{array}$ & $\begin{array}{l}\text { Current } \\
\text { flow }\end{array}$ & $\begin{array}{l}\text { Equalization step time } \\
\text { (s) }\end{array}$ & $\begin{array}{l}\text { SoC root mean } \\
\text { square }\end{array}$ \\
\hline 1 & C-P & 134 & 5.603933 & C-P & 115 & 5.603859 \\
\hline 3 & C-P & 274 & 5.358384 & C-P & 263 & 5.41716 \\
\hline 4 & $\mathrm{P}-\mathrm{C}$ & 290 & 5.099128 & $\mathrm{P}-\mathrm{C}$ & 406 & 5.067089 \\
\hline 5 & C-P & 609 & 4.601761 & C-P & 541 & 4.604459 \\
\hline 8 & C-P & 278 & 3.056487 & C-P & 191 & 2.915479 \\
\hline 9 & C-P & 2 & 3.056817 & $\mathrm{P}-\mathrm{C}$ & 81 & 2.894169 \\
\hline 10 & C-P & 34 & 3.060231 & $\mathrm{P}-\mathrm{C}$ & 179 & 2.714171 \\
\hline 11 & $\mathrm{P}-\mathrm{C}$ & 162 & 2.920538 & P-C & 188 & 2.593799 \\
\hline 12 & C-P & 763 & 0.420451 & C-P & 646 & 0.543427 \\
\hline 13 & $\mathrm{x}$ & $\mathrm{x}$ & $\mathrm{x}$ & $\mathrm{P}-\mathrm{C}$ & 65 & 0.473376 \\
\hline
\end{tabular}

* C-P (Cell to Pack) means current goes from single cell to pack, P-C (Pack to Cell) means current goes from pack to single cell.

TABLE IV

COMPARISON RESULTS OF EQUALIZATION IN GROUP 1

\begin{tabular}{cccccc}
\hline Method & Battery & Initial SoC gap (\%) & Final SoC gap (\%) & Equalization time (h) & System energy loss (Wh) \\
\hline Proposed PSO method & $5 \mathrm{Ah} / 3.2 \mathrm{~V}$ & 20.4 & 1.1 & 0.98 & 3.61544 \\
Method 1 [20] & $5 \mathrm{Ah} / 3.2 \mathrm{~V}$ & 20.4 & 1.4 & 1.12 & 4.36960 \\
\hline
\end{tabular}

TABLE V

COMPARISON RESULTS OF EQUALIZATION IN GROUP 2

\begin{tabular}{cccccc}
\hline Comparison & Method & Battery & Initial SoC gap (\%) & Final SoC gap (\%) & Equalization time (h) \\
\hline Group 2-1 & PSO method & $2.6 \mathrm{Ah} / 3.7 \mathrm{~V}$ & 21.3 & 1.5 & 0.46 \\
& Method 2 [14] & $2.6 \mathrm{Ah} / 3.7 \mathrm{~V}$ & 21.3 & 5.8 & 2.5 \\
Group 2-2 & PSO method & $5 \mathrm{Ah} / 3.2 \mathrm{~V}$ & 15.8 & 2.4 & 2.34 \\
& Method 3 [16] & $5 \mathrm{Ah} / 3.2 \mathrm{~V}$ & 15.8 & 6 & 7.2 \\
\hline
\end{tabular}

and $\mathrm{I}_{\text {discharge }}^{\prime}$ are the currents that go through the single cell and the other cells in the discharge mode respectively .

To simplify the analysis, the pack voltage is assumed to be $\mathrm{n} \times \mathrm{V}$, and the voltage of cells $\mathrm{i}$ and $\mathrm{j}$ is $\mathrm{V}$. Thus, these two equations can be expressed as follows:

$$
\begin{gathered}
W_{\text {cha_loss }}=\mathrm{V} \cdot \sum_{\mathrm{i}=1}^{p}\left[(\mathrm{n}+1) \mathrm{I}_{\text {charge }}^{\prime}-\mathrm{I}_{\text {charge }}\right] \cdot t_{i}, \\
W_{\text {disch_loss }}=\mathrm{V} \cdot \sum_{\mathrm{j}=1}^{q}\left[\mathrm{I}_{\text {discharge }}-(\mathrm{n}+1) \mathrm{I}_{\text {discharge }}^{\prime}\right] \cdot t_{j} .
\end{gathered}
$$

The total energy loss is as follows:

$$
W_{\text {total }}=W_{\text {cha_loss }}+W_{\text {disch_loss }} \text {. }
$$

Taking Eqs. (19) and (20) into Eq. (21):

$$
\begin{aligned}
& W_{\text {total }}=\mathrm{V} \cdot\left[(\mathrm{n}+1) \mathrm{I}_{\text {charge }}^{\prime}-\mathrm{I}_{\text {charge }}\right] \sum_{\mathrm{i}=1}^{p} t_{i}+, \\
& \mathrm{V} \cdot\left[\mathrm{I}_{\text {discharge }}-(\mathrm{n}+1) \mathrm{I}_{\text {discharge }}^{\prime}\right] \sum_{\mathrm{j}=1}^{q} t_{j} .
\end{aligned}
$$

If $\quad t_{\text {total }}=\sum_{\mathrm{i}=1}^{p} t_{i}+\sum_{\mathrm{j}=1}^{q} t_{j}$, Eq. (22) can be expressed as

$$
\begin{aligned}
& W_{\text {total }}=\mathrm{V} \cdot\left[(\mathrm{n}+1) \mathrm{I}_{\text {cha }}^{\prime}-\mathrm{I}_{\text {cha }}\right] t_{\text {total }}+ \\
& \mathrm{V} \cdot\left\{\left[\mathrm{I}_{\text {disch }}-(\mathrm{n}+1) \mathrm{I}_{\text {disch }}^{\prime}\right]-\left[(\mathrm{n}+1) \mathrm{I}_{\text {cha }}^{\prime}-\mathrm{I}_{\text {cha }}\right]\right\} \sum_{\mathrm{j}=1}^{q} t_{j} .
\end{aligned}
$$

Evidently, the total energy loss is determined by two parts for a specific bi-directional equalization system: the first part is the total equalization time, and the second part is the extreme value of the total equalization for all the discharge cells. Whether $\sum_{\mathrm{j}=1}^{q} t_{j}$ take a maximum or minimum depends on the sign of $\mathrm{V} \cdot\left\{\left[\mathrm{I}_{\text {disch }}-(\mathrm{n}+1) \mathrm{I}_{\text {disch }}^{\prime}\right]-\left[(\mathrm{n}+1) \mathrm{I}_{\text {cha }}^{\prime}-\mathrm{I}_{\text {cha }}\right]\right\}$. Moreover, when the number of cells for charging and discharging increases, energy loss increases. Therefore, reducing the equalization time and steps is helpful to lower the system energy loss.

\section{CONCLUSION}

In lithium-ion battery applications, equalization time increases along with an increase in cell capacity. A PSO-optimized equalization algorithm for bidirectional 
equalization topologies was proposed in this study to decrease time and energy loss during equalization. The proposed algorithm took the pack SoC distribution as input to seek the global optimal solution with fitness function and limitations. In addition, the global solution ensured that the equalization time was short with excellent SoC consistency. To verify the effectiveness of the proposed algorithm, a pack with 12 cells was tested. The experimental results showed that the available pack capacity was enhanced by $13.2 \%$. Comparative experiments were also taken between the traditional methods and the proposed PSO algorithm. The proposed algorithm was superior to traditional methods in terms of equalization time, final SoC consistency, and energy loss.

Further studies will focus on the influence of cell SoC variation. Moreover, some improvements will be applied to the PSO algorithm.

\section{ACKNOWLEDGMENT}

This research was partially supported by the Research and Development of Application Technology Plan Project in Heilongjiang Province of China (GA13A202), the NSFC-EPSRC Collaborative Research Initiative in Smart Grids and the Integration of Electric Vehicles (51361130153), and the Science and Technology Project of State Grid Corporation of China.

\section{REFERENCES}

[1] B. Scrosati and J. Garche, "Lithium batteries: Status, prospects and future,” Journal of Power Sources, Vol. 195, No. 9, pp. 2419-2430, May 2010.

[2] G. J. Offer, V. Yufit, D. A. Howey, B. Wu, and N. P. Brandon, "Module design and fault diagnosis in electric vehicle batteries,” Journal of Power Sources, Vol. 206, pp. 383-392, May 2012.

[3] B. Kenney, K. Darcovich, D. D. MacNeil, and I. J. Davidson, "Modelling the impact of variations in electrode manufacturing on lithium-ion battery modules," Journal of Power Sources, Vol. 213, pp. 391-401, Sep. 2012.

[4] J. Kim, J. Shin, C. Chun, and B. H. Cho, "Stable configuration of a li-ion series battery pack based on a screening process for improved voltage/SOC balancing," IEEE Trans. Power Electron., Vol. 27, No. 1, pp. 411-424, Jan. 2012.

[5] Y. Zheng, M. Ouyang, L. Lu, J. Li, X. Han, and L. Xu, "On-line equalization for lithium-ion battery packs based on charging cell voltages: Part 1. Equalization based on remaining charging capacity estimation," Journal of Power Sources, Vol. 247, pp. 676-686, Feb. 2014.

[6] M. Kim, C. Kim, J. Kim, and G. Moon, “A chain structure of switched capacitor for improved cell balancing speed of lithium-ion batteries,” IEEE Trans. Ind. Electron., Vol. 61, No. 8, pp. 3989-3999, Aug. 2014.

[7] J. Gallardo-Lozano, E. Romero-Cadaval, M. I. Milanes-Montero, and M. A. Guerrero-Martinez, "Battery equalization active methods," Journal of Power Sources, Vol. 246, pp. 934-949, Jan. 2014.
[8] N. H. Kutkut and D. M. Divan, "Dynamic equalization techniques for series battery stacks,” Intelec-Eighteenth International Telecommunications Energy Conference, pp. 514-521, 1996.

[9] R. Lu, C. Zhu, L. Tian, and Q. Wang, "Super-capacitor stacks management system with dynamic equalization techniques,” IEEE Trans. Magn., Vol. 43, No. 1, pp. 254-258, Jan. 2007.

[10] C. H. Kim, M. Y. Kim, and G. W. Moon, “A modularized charge equalizer using a battery monitoring IC for series-connected Li-ion battery strings in electric vehicles,” IEEE Trans. Power Electron., Vol. 28, No. 8, pp. 3779-3787, Aug. 2013.

[11] M. Einhorn, W. Roessler, and J. Fleig, "Improved performance of serially connected Li-ion batteries with active cell balancing in electric vehicles,” IEEE Trans. Veh. Technol., Vol. 60, No. 6, pp. 2448-2457, Jul. 2011.

[12] P. A. Cassani and S. S. Williamson, "Design, testing, and validation of a simplified control scheme for a novel plug-in hybrid electric vehicle battery cell equalizer," IEEE Trans. Ind. Electron., Vol. 57, No. 12, pp. 3956-3962, Dec. 2010.

[13] C. Lim, K. Lee, N. Ku, D. Hyun, and R. Kim, “A modularized equalization method based on magnetizing energy for a series-connected lithium-ion battery string," IEEE Trans. Power Electron., Vol. 29, No. 4, pp. 1791-1799, Apr. 2014.

[14] S. H. Park, K. B. Park, H. S. Kim, G. W. Moon, and M. J. Youn, "Single-magnetic cell-to-cell charge equalization converter with reduced number of transformer windings," IEEE Trans. Power Electron., Vol. 27, No. 6, pp. 2900-2911, Jun. 2012.

[15] Y. S. Lee, Y. P. Ko, M. W. Cheng, and L. J. Liu, "Multiphase zero-current switching bidirectional converters and battery energy storage application,” IEEE Trans. Power Electron., Vol. 28, No. 8, pp. 3806-3815, Aug. 2013.

[16] Y. Guo, R. Lu, G. Wu, and C. Zhu, "A high efficiency isolated bidirectional equalizer for Lithium-ion battery string," 2012 IEEE Vehicle Power and Propulsion Conference (VPPC 2012), pp. 962-966, 2012.

[17] P. A. Cassani and S. S. Williamson, "Feasibility analysis of a novel cell equalizer topology for plug-in hybrid electric vehicle energy-storage systems," IEEE Trans. Veh. Technol., Vol. 58, No. 8, pp. 3938-3946, Oct. 2009.

[18] A. C. Baughman and M. Ferdowsi, "Double-tiered switched-capacitor battery charge equalization technique," IEEE Trans. Ind. Electron., Vol. 55, No. 6, pp. 2277-2285, Jun. 2008.

[19] B. Dong and Y. H. Han, "A new architecture for battery charge equalization," 2011 IEEE Energy Conversion Congress and Exposition(ECCE), pp. 928-934, 2011.

[20] L. Maharjan, S. Inoue, H. Akagi, and J. Asakura, "State-of-charge (SOC)-balancing control of a battery energy storage system based on a cascade PWM converter,” IEEE Trans. Power Electron., Vol. 24, No. 6, pp. 1628-1636, May/Jun. 2009.

[21] M. Charkhgard and M. Farrokhi, "State-of-charge estimation for lithium-ion batteries using neural networks and EKF,” IEEE Trans. Ind. Electron., Vol. 57, No. 12, pp. 4178-4187, Dec. 2010.

[22] M. A. Roscher, J. Assfalg, and O. S. Bohlen, "Detection of utilizable capacity deterioration in battery systems," IEEE Trans. Veh. Technol., Vol. 60, No. 1, pp. 98-103, Jan. 2011. 
[23] C. Speltino, A. Stefanopoulou, and G. Fiengo, "Cell equalization in battery stacks through state of charge estimation polling,” 2010 American Control Conference, pp. 5050-5055, 2010.

[24] J. Kennedy and R. Eberhart, "Particle swarm optimization," in IEEE International Conference on Neural Networks, Vol. 4, pp. 1942-1948, 1995.

[25] S. Yuhui and R. Eberhart, "A modified particle swarm optimizer," in The 1998 IEEE International Conference on Evolutionary Computation, pp. 69-73, 1998.

[26] M. Einhorn, W. Guertlschmid, T. Blochberger, R. Kumpusch, R. Permann, F. V. Conte, C. Kral, and J. Fleig, "A current equalization method for serially connected battery cells using a single power converter for each cell," IEEE Trans. Veh. Technol., Vol. 60, No. 9, pp. 4227-4237, Nov. 2011.

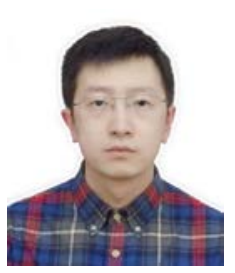

Jinlei Sun was born in Harbin, China, on February 17, 1985. He received his B.S. degree in Agricultural Electrification and Automation from Northeast Agricultural University, Harbin in 2008, and his M.S. degree in Power Electronics and Electrical Drive from Harbin University of Science and Technology in 2011. He is currently working toward his Ph.D. degree. His current research interests include battery equalization technology for EV/HEV and battery thermal management at low temperature.

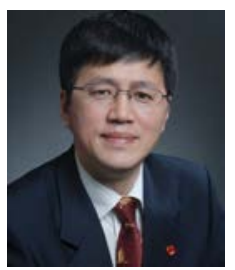

Chunbo Zhu was born in Harbin, China, on February 12, 1964. He received his B.S. and M.S. degrees in Electrical Engineering and his Ph.D. degree in Mechanical Engineering from Harbin Institute of Technology (HIT), Harbin, in 1987, 1992, and 2001, respectively. He has been a lecturer in the Department of Automation Measurement and Control in HIT since 1987. He was a post-doctoral research fellow with the PEI Research Center, National University of Ireland, Galway, Ireland, from 2003 to 2004. He is currently a full professor at HIT and leads the Laboratory of Energy Management Technology in the Electric Vehicle Research Center. His current research interests include energy management systems, electric and hybrid electric vehicles, and wireless energy transfer technologies.

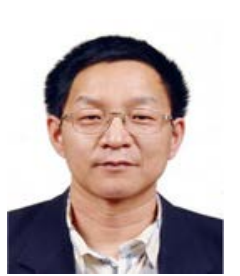

Rengui Lu was born in Heilongjiang, China, on January 19, 1967. He received his M.Sc. and Ph.D. degrees in Instrument Science and Technology from Harbin Institute of Technology (HIT), Harbin, China, in 1992 and 2008, respectively. He has been an associate professor in the Department of Automation Measurement and Control Engineering in HIT. His current research interests include energy management systems, electric and hybrid electric vehicles, and wireless energy transfer technologies.

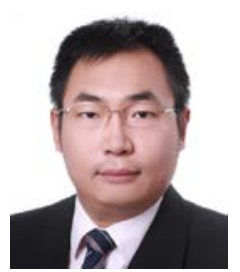

Kai Song received his B.S., M.S., and Ph.D. degrees in Instrument Science and Technology from Harbin Institute of Technology (HIT), Harbin, China, in 2005, 2007, and 2011, respectively. He has been a lecturer with the School of Electrical Engineering and Automation in HIT since 2011, and a post-doctoral research fellow with the State Key Laboratory of Robotics and System in HIT since 2013. He is currently a visiting scholar in electrical engineering in the University of Tokyo, Japan. His current research interests include wireless power transfer, wireless communication, and battery management system.

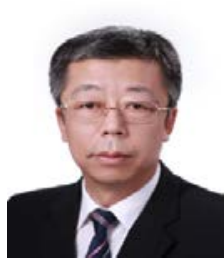

Guo Wei was born in Liaoning Province, China, in 1966. He received his B.S. and M.S. degrees in Electromagnetic Measurement and Instruments from Harbin Institute of Technology, China, in 1988 and 1991 respectively, and his Ph.D. degree in Scientific Research from Saga University, Japan, in 2003. He is currently a professor in the School of Electrical Engineering and Automation at Harbin Institute of Technology. His research interests include modern sensor technique, intelligent testing theory and its application, and battery management system. 